\title{
S5ynthesis
}

International Scientific Conference of IT and Business-Related Research

\section{ZNAČAJ MEĐUORGANIZACIONIH ODNOSA ZA KREIRANJE ZAJEDNIČKE VREDNOSTI}

\section{THE IMPORTANCE OF INTER-ORGANIZATIONAL RELATIONSHIPS FOR SHARED VALUE CREATION}

\author{
Mirjana Petković ${ }^{1}$, Snežana Lazarević 2 , Jelena Lukić ${ }^{2}$ \\ ${ }^{1}$ Ekonomski fakultet, Univerzitet u Beogradu, Srbija \\ ${ }^{2}$ Fakultet za fizičku kulturu i menadžment u sportu, Univerzitet Singidunum, Beograd, Srbija
}

\begin{abstract}
Apstrakt:
Cilj ovog rada jeste da ukaže na značaj međuorganizacionih odnosa prilikom kreiranja zajedničke vrednosti. Kompanije sve više uvažavaju činjenicu da njihove strategije ne mogu biti izolovane od zajednica u kojima posluju, da moraju uzeti u obzir društvene izazove i saradnjom sa različitim partnerima težiti ka novim poslovnim modelima i strategijama koje će im obezbediti dugoročnu konkurentnost uz istovremeno zadovoljenje ciljeva zajednice. U osnovi koncepta zajedničke vrednosti nalazi se strategija međuorganizacionih odnosa. Radi se o novom strateškom pokušaju menadžera da pronađu nove potencijale za rast i razvoj, a pre svega za opstanak na poslovnoj sceni. U suštini ove strategije je proces saradnje pomoću kojeg različiti učesnici u međuorganizacionom odnosu posmatraju probleme iz različitih perspektiva i pronalaze zajedničko rešenje koje je superiornije od rešenja do kojeg bi samostalno došli, gradeći dugoročnu konkurentnost uz istovremeno zadovoljavanje društvenih ciljeva. Nesumnjivo je da su za kreiranje strategije i organizacije međuorganizacionih odnosa potrebni menadžeri sa novim znanjima, sposobnostima i veštinama, ali i konstituisanje posebnog međuorganizacionog dizajna koji će predstavljati podršku za realizaciju strategije međuorganizacionih odnosa.
\end{abstract}

\section{Ključne reči:}

strategija međuorganizacionih odnosa, međuorganizacioni dizajn, zajednička vrednost, liderstvo.

\section{UVOD}

Primenom koncepta zajedničke vrednosti (shared value), kompanije nastoje da identifikuju područja u kojima se interesi svih zainteresovanih strana u velikoj meri preklapaju i teže da kreiraju vrednost ne samo za kompaniju, već i za zajednicu u kojoj posluju. Samim tim, kompanije moraju sarađivati sa brojnim partnerima: proizvođačima, dobavljačima, kupcima, istraživačko-razvojnim organizacijama, univerzitetima, pa čak i konkurentima. Interes za primenom strategija međuorganizacionog povezivanja kompanije su videle u brojnim prednostima koje mogu ostvariti udruživanjem sa partnerima: smanjenje troškova, pristup novim tehnologijama, veća produktivnost i kvalitet, brže i efikasnije učenje, smanjenje rizika, za kraće vreme mogu doći do inovacija i novih tržišta koje će im stvoriti dugoročnu konkurentsku prednost, a kroz saradnju sa partnerima one istovremeno mogu doprineti i realizaciji viših ciljeva zajednice u kojoj posluju. Sa druge strane, primena strategija međuorganizacionih odnosa zahteva promene u organizacionom dizajnu kompanije u skladu sa Čendlerovom hipotezom

\section{Abstract:}

The aim of this paper is to highlight the importance of inter-organizational relationships when creating shared value. Companies are becoming more and more aware of the fact that their strategies cannot be isolated from the communities in which they operate, and that they must take into account social challenges, and cooperate with various partners in order to develop new business models and strategies that will ensure long-term competitiveness and satisfy the goals of the community. The strategy of inter-organizational relationships represents the focal point of the shared value concept. Those strategies represent a new strategy in which managers attempt to find new potential resources for further growth and development, and survival on the business market. The essential part of this strategy is the process of cooperation that enables different participants in inter-organizational relationships to observe problems from different perspectives and find more efficient mutual solutions, by building long-term competitiveness and satisfying social objectives. There is no doubt that the creation of strategy and organization of inter-organizational relationships requires managers with new knowledge, abilities and skills, but also creation of a special inter-organizational design that will provide necessary support for the implementation of inter-organizational relationship strategy.

\section{Key words:}

inter-organizational relationship strategy, inter-organizational design, shared value, leadership.

da "struktura prati strategiju" (Chendler, 1962). Pre svega, lideri i menadžeri moraju steći nova znanja i veštine da bi uspešno implementirali nove strategije pomoću međuorganizacionog dizajna sa ciljem da kroz brojne vidove saradnje kreiraju zajedničku vrednost. Cilj ovog rada je da:

1) predstavi ključne aktivnosti pomoću kojih kompanije mogu kreirati zajedničku vrednost;

2) ukaže na značaj međuorganizacionog dizajna prilikom primene strategije međuorganizacionih odnosa sa ciljem kreiranja zajedničke vrednosti;

3) identifikuje ključne faktore uspeha uspostavljenog međuorganizacionog odnosa.

U radu je prvo objašnjen koncept zajedničke vrednosti i prikazan okvir aktivnosti koji može poslužiti kao putokaz liderima savremenih kompanija za uspešnu implementaciju ovog koncepta. Zatim je ukazano na značaj i ulogu strategije međuorganizacionih odnosa i prikazane su ključne karakteristike međuorganizacionog dizajna koji treba da predstavlja podršku za realizaciju strategije. Završni deo rada je posvećen ključnim faktorima koji determinišu uspeh uspostavljenih međuorganizacionih odnosa. 


\section{KREIRANJE ZAJEDNIČKE VREDNOSTI}

Koncept zajedničke vrednosti su prvi put pomenuli Majkl Porter i Mark Kramer u svom radu "Strategija i društvo" u časopisu Harvard Business Review 2006. godine. Pet godina kasnije, autori su dali i definiciju ovog koncepta po kojoj zajednička vrednost predstavlja "politike i operativne procedure kojima se poboljšava konkurentska prednost kompanija uz istovremeni napredak ekonomskih i društvenih uslova zajednica u kojima te kompanije posluju" (Porter \& Kramer, 2011, str. 66). Kreiranje zajedničke vrednosti se ne odnosi na preraspodelu postojeće vrednosti, već na iznalaženje novih načina za kreiranje veće vrednosti koja se potom deli na više zainteresovanih strana (Maltz \& Schein, 2012, str. 58). Investiranjem u poboljšanje zdravlja, unapređenje obrazovanja i veću produktivnost, kompanije na indirektan način proširuju svoju bazu kupaca i povećavaju njihovu kupovnu moć, jer građani duže žive, kvalitet životnog standarda raste i oni postaju platežno sposobniji. Sa druge strane, svaki put kada kompanije uzmu u obzir aktuelne društvene probleme i posmatraju ih kao ključni deo svoje konkurentske strategije, one ne samo da postižu dugoročnu prednost, već preduzimaju i održive promene u društvu (Vaidyanathan \& Scott, 2012) što predstavlja jedan od imperativa u savremenom načinu poslovanja. Zdravo društvo ima veća očekivanja i potrebu za sve kvalitetnijim proizvodima i uslugama što pruža velike mogućnosti za uspešne kompanije. Kao što je tvrdio Piter Draker "zdrava kompanija i bolesno društvo su retko kada spojivi. Zdrave kompanije zahtevaju zdravo društvo" (Drucker, 2001, str. 46). Da bi iskoristile sve mogućnosti iz okruženja, strategije kompanije moraju integrisati i društvenu perspektivu, jer svaka aktivnost u lancu vrednosti ima uticaj na zajednicu u kojoj ta kompanija posluje, a koji može biti pozitivan i negativan (Porter \& Kramer, 2006).

Bitno je povući jasnu demarkacionu liniju između koncepta zajedničke vrednosti i korporativne društvene odgovornosti posmatranjem različitih faktora: motivacije, pokretača, merila performansi, odgovornosti, društvenih koristi ali i koristi za samu kompaniju od primene datih koncepata (Tabela 1). Dok se u osnovi korporativne društvene odgovornosti nalaze: reputacija, eksterne zainteresovane strane, troškovi, posebno formirani departmani za korporativnu društvenu odgovornost i smanjenje rizika, koncept kreiranja zajedničke vrednosti je podstaknut korporativnom strategijom sa ciljem ostvarenja konkurentske prednosti kroz nove poslovne mogućnosti i dugoročnu održivu promenu koja je inicirana na svim nivoima kompanije.

\begin{tabular}{|c|c|c|}
\hline & $\begin{array}{c}\text { Korporativna } \\
\text { društvena odgovornost }\end{array}$ & $\begin{array}{l}\text { Kreiranje zajedničke } \\
\text { vrednosti }\end{array}$ \\
\hline Motivacija & $\begin{array}{l}\text { Korporativna repu- } \\
\text { tacija }\end{array}$ & $\begin{array}{c}\text { Konkurentska pred- } \\
\text { nost }\end{array}$ \\
\hline Pokretači & Eksterni stejkholderi & $\begin{array}{l}\text { Korporativna strate- } \\
\text { gija }\end{array}$ \\
\hline Merila & $\begin{array}{c}\text { Troškovi, standardna } \\
\text { merila }\end{array}$ & $\begin{array}{c}\text { Socijalna i ekonomska } \\
\text { vrednost }\end{array}$ \\
\hline Menadžment & $\begin{array}{l}\text { Departmani za kor- } \\
\text { porativnu društvenu } \\
\text { odgovornost }\end{array}$ & $\begin{array}{l}\text { Na nivou cele kom- } \\
\text { panije }\end{array}$ \\
\hline $\begin{array}{l}\text { Društvene } \\
\text { koristi }\end{array}$ & Uspešni projekti & $\begin{array}{c}\text { Dugoročna održiva } \\
\text { promena }\end{array}$ \\
\hline $\begin{array}{l}\text { Koristi za kom- } \\
\text { paniju }\end{array}$ & $\begin{array}{l}\text { Smanjenje rizika i rast } \\
\text { gudvila }\end{array}$ & $\begin{array}{l}\text { Nove poslovne } \\
\text { mogućnosti }\end{array}$ \\
\hline
\end{tabular}

Tabela 1. Poređenje korporativne društvene odgovornosti i koncepta zajedničke vrednosti

Izvor: Vaidyanathan \& Scott (2012)
Osnova za kreiranje zajedničke vrednosti i posledično konkurentske prednosti leži u inovacijama, s obzirom na činjenicu da inovacije označavaju nešto novo, bilo da je reč o novom proizvodu, usluzi, novom metodu proizvodnje, prodoru na novo tržište, novom izvoru snabdevanja, novom načinu organizovanja ili primeni već neke postojeće ideje na nov način (Schumpeter, 1934).

Kompanije mogu kreirati zajedničku vrednost na više načina. Tri ključna načina su (Porter \& Kramer, 2011):

1. Preispitivanjem proizvoda i tržišta. Kompanije mogu rešiti društvene potrebe razvojem inovativnijih proizvoda i usluga koji bolje zadovoljavaju potrebe na postojećim tržištima ili omogućavaju prodor na nova tržišta.

2. Preispitivanjem lanca vrednosti. Kompanije mogu da poboljšaju kvalitet, količinu, troškove, pouzdanost uloženih sredstava, proces proizvodnje i distribucije uz istovremeno pozitivno delovanje na prirodne resurse, ekonomski i društveni razvoj.

3. Omogućavanjem razvoja lokalnih klastera. Kompanije ne posluju izolovano od svog okruženja, već grade čvrste odnose sa brojnim partnerima.

Svaka kompanija ima svoj individualni pristup kreiranju zajedničke vrednosti koji je specifičan za njenu poslovnu strategiju i karakteristike zajednice u kojima posluje. Ipak, vremenom je definisan opšti okvir koji liderima može da posluži kao smernica za uspešnu primenu ovog koncepta (Tabela 2).

\section{VIZIJA:}

Jasna vizija kompanije predstavlja pokretačku osnovu za kreiranje zajedničke vrednosti

Odbor direktora i lideri vide posvećenost zajednici kao sastavni deo strategije

\section{STRATEGIJA}

Potrebno je da strategija ima jasan fokus i da su definisani ambiciozni ali realni ciljevi

Fokus na ključnim faktorima za

kreiranje zajedničke vrednosti

... za koje su definisani ambiciozni i realni ciljevi za kreiranje zajedničke vrednosti

SARADNJA SA PARTNERIMA

Efektivna saradnja različitih učesnika unutar i izvan kompanije

\begin{tabular}{|c|c|c|c|c|c|}
\hline \multicolumn{2}{|c|}{$\begin{array}{c}\text { Procena ključnih resursa } \\
\text { koje partneri poseduju: fi- } \\
\text { nansije, znanje, ekspertiza, } \\
\text { politički i poslovni uticaj }\end{array}$} & \multicolumn{2}{|c|}{$\begin{array}{l}\text { Holističko } \\
\text { upravljanje svim } \\
\text { naporima unutar } \\
\text { kompanije }\end{array}$} & \multicolumn{2}{|c|}{$\begin{array}{c}\text { Mobilizacija partnera } \\
\text { i podsticanje na akciju } \\
\text { ka kreiranju zajedničke } \\
\text { vrednosti }\end{array}$} \\
\hline \multicolumn{6}{|c|}{$\begin{array}{l}\text { MERENJE PERFORMANSI: } \\
\text { Uspostaviti adekvatan menadžment performansi }\end{array}$} \\
\hline $\begin{array}{l}\text { Aktivno mer- } \\
\text { enje relevantnih } \\
\text { pokazatelja }\end{array}$ & $\begin{array}{l}\text { Unapr } \\
\text { merila } \\
\text { forma } \\
\text { osnovu i }\end{array}$ & $\begin{array}{l}\text { eđenje } \\
\text { a per- } \\
\text { nsi na } \\
\text { iskustva }\end{array}$ & $\begin{array}{r}\text { Usmeriti n } \\
\text { velikim is } \\
\text { društven } \\
\text { zovil }\end{array}$ & $\begin{array}{l}\text { apore ka } \\
\text { loženim } \\
\text { im iza- } \\
\text { na }\end{array}$ & $\begin{array}{l}\text { Interna i ekster- } \\
\text { na komunikaci- } \\
\text { ja ostvarenih } \\
\text { rezultata }\end{array}$ \\
\hline
\end{tabular}

Tabela 2. Okvir za kreiranje zajedničke vrednosti

Izvor: Adaptirano prema Vaidyanathan \& Scott (2012)

Jedna od determinanti za kreiranje zajedničke vrednosti jeste sposobnost kompanija da uspostavljaju različite međuorganizacione odnose sa brojnim partnerima iz okruženja. Kompanije 
postaju svesne da ne mogu da budu nefleksibilne i zatvorene u svoja četiri zida, već da moraju otvoriti svoje tradicionalne granice, učiniti ih adaptibilnim i poroznim, redefinisati strategiju i reorganizovati svoju postojeću organizacionu strukturu. Moraju se okrenuti različitim oblicima saradnje i partnerstava sa spoljnim stejkholderima (O’Leary \& Bingham, 2007, str. 7). One su shvatile da danas, za uspešno poslovanje u složenom i neizvesnom okruženju punom opasnih suparnika "nije dobro biti usamljen" (Ohmae, 1989).

\section{MEĐUORGANIZACIONI ODNOSI}

Praksa povezivanja i saradnje organizacija po raznim osnovama nije nepoznata u menadžmentu i organizaciji, ali je njena priroda danas bitno promenjena (Petković \& Lazarević, 2012, str. 56). Savremene kompanije su međuorganizacione odnose prepoznale kao novi izvor rasta i razvoja. Međuorganizacioni odnosi predstavljaju relativno trajne veze i odnose, kao i tokove informacija i znanja koji se odvijaju između dve ili više organizacija (Oliver, 1990). Pregledom literature, moguće je identifikovati više vrsta međuorganizacionih odnosa. Jednu od značajnijih tipologija su predložili Todeva i Knoke koji ukazuju na postojanje trinaest vrsta međuorganizacionih odnosa: hijerarhijske veze (akvizicije i merdžeri), zajednička ulaganja, kapitalna ulaganja, kooperative, konzorcijumi za istraživanje i razvoj, strateški kooperativni sporazumi, karteli, franšizing, licenciranje, mreže podugovarača, grupe za industrijske standarde, akcione grupe, i tržišni odnosi (Todeva \& Knoke, 2005, str. 3). Bez obzira na vrstu uspostavljenog međuorganizacionog odnosa, ključna prednost jeste u tome što kroz uspostavljeno partnerstvo različiti učesnici posmatraju probleme iz različitih perspektiva i konstruktivno pronalaze rešenje koje je superiornije od rešenja do kojeg bi samostalno došli (Gray, 1989).

U junu 2012. godine, Coca-Cola, Ford Motor, Heiny, Nike $i$ Procter \& Gamble su formirali stratešku radnu grupu za razvoj ambalaže od biljnih PET materijala i vlakana, pod nazivom "Plant PET Technology Collaborative" - PTC. PET je izdržljiva, lagana plastika koja se koristi za različite proizvode i materijale, plastične boce, odeću, obuću, automobilske tkanine i tepihe u svim zemljama u kojima ove kompanije posluju. Intenzivnim istraživačko-razvojnim aktivnostima koje zajedničkim snagama sprovode udružene kompanije dolazi do brojnih promena i u drugim industrijama jer se razvijaju novi standardi i koncepti koji će morati da se poštuju (Caliendo, 2012).

Postoje brojni empirijski dokazi da adekvatno uspostavljeni međuorganizacioni odnosi utiču na poslovanje kompanija (Schreiner \& Corsten, 2004): pre svega na kreiranje i razmenu informacija i znanja, inovativnost i kreiranje vrednosti u okviru same kompanije. Za mlade kompanije kojima nedostaje reputacija i koje imaju ograničene resurse i poteškoće u suočavanju sa stalno menjajućim okruženjem, značaj međuorganizacionog povezivanja je još veći jer pomoću uspostavljenih partnerstava one mogu steći reputaciju, dobiti resurse i naučnu ekspertizu (Koput \& Powell, 2004). Krajem XX i početkom XXI veka uvreženi su stavovi lidera i menadžera uspešnih kompanija da se saradnjom može postići gotovo sve, jer organizacije nisu ograničene sopstvenim resursima i ekspertizom (Huxham \& Vangen, 2005, str. 3) i da stupanje u međuorganizacione odnose postaje faktor od suštinske važnosti za uspeh.
Novartis je mogućnosti za kreiranje zajedničke vrednosti video u prodaji svojih lekova u ruralnoj Indiji u kojoj živi 70\% svetske populacije. Prepreka nije bila cena koju su naplaćivali, već socijalni uslovi u celom regionu: hronični nedostatak svesti o značaju zdravlja, neadekvatna obuka za zdravstvene usluge i nekoliko hiljada lokalnih bolnica bez pouzdanog lanca snabdevanja. Sve ove probleme, Novartis je video kao svoje poslovne mogućnosti. Zaposlio je hiljadu ljudi za poslove edukacije, formirao kampove za obuku i trening, i izgradio distributivne sisteme za 50.000 ruralnih bolnica... Novartisov rezultat je bio potpuno nov poslovni model za budućnost, obzirom da se predviđa da će u narednoj deceniji, tržišta zemalja u razvoju sa sličnim karakteristikama činiti 75\% ukupnog rasta prodaje u farmaceutskoj industriji na globalnom nivou, a da je 42 miliona stanovnika Indije dobilo znatno bolji kvalitet zdravstvene usluge, koji do tada nisu mogli da obezbede ni vlada ni razne nevladine organizacije (Kramer, 2012).

\section{MEĐUORGANIZACIONI DIZAJN}

Uspeh strategije međuorganizacionih odnosa u smislu kreiranja zajedničke vrednosti upravo zavisi od efikasnosti modela međuorganizacione strukture. U procesu izbora modela i kreiranja njegovih komponenti treba poštovati gore pomenuto klasično Čendlerovo pravilo "struktura prati strategiju", a zatim kreirati sisteme i procese koji će stajati iza ovog modela i biti njegova stabilna podrška. Interes za organizacionim dizajnom je došao do izražaja poslednjih nekoliko decenija. Jedan od razloga je taj što su organizacije vremenom postajale sve složenije. Disciplina organizacionog dizajna je evoluirala zajedno sa rastućom složenošću organizacija i željom da se kreiraju organizacije visokih performansi (Galbraith, 2010). Promena fokusa sa hijerarhije i zatvorenosti na saradnju i otvorenost, zahteva od kompanija da promene ključne elemente uspostavljenog organizacionog dizajna: strategiju, strukturu, poslovne procese, politike ljudskih resursa, sisteme nagrađivanja, liderstvo i organizacionu kulturu. Najjednostavnije rečeno, organizacioni dizajn se odnosi na aktivnosti određivanja i sprovođenja strategijskog plana. U tom smislu, ključni cilj organizacionog dizajna je da izvrši podelu rada i uspostavi mehanizme saradnje tako da se odluke donose na osnovu što kvalitetnijih informacija dok se istovremeno troškovi koordinacije održavaju na što nižem nivou (Grundei, 2006). Adekvatnim dizajniranjem, organizacije mogu steći sposobnosti da se blagovremeno prilagođavaju promenama u okruženju (Eriksen, 2006, str. 165) kroz efikasan tok informacija.

Imajući u vidu činjenicu da izbor strategije utiče na organizacioni dizajn koji predstavlja podršku za realizaciju definisanih ciljeva (Daft, 2009, str. 72), strategija međuorganizacionih odnosa podrazumeva slojevito organizaciono prilagođavanje partnera. Organizacioni dizajn treba da omogući organizaciji da se izbori sa neizvesnošću okruženja ne samo kroz efikasan tok informacija kroz celu organizaciju (Grundei, 2006, str. 46), već i između svih članova međuorganizacionog odnosa, što posledično pozicionira strukturu organizacije na mesto bitnog faktora koji determiniše uspeh međuorganizacionog odnosa (Osborn \& Baughn, 1990).

Slika 1 jasno pokazuje da je u toku procesa dizajniranja međuorganizacionog odnosa potrebno posmatrati strukturu svake kompanije kao sistem komunikacija i procesiranja informacija između svih zaposlenih koji zajedničkim interakcijama čine 
posebnu međuorganizacionu mrežu kompleksne kompanije (Petković \& Lazarević, 2012). U internom organizacionom dizajnu mora doći do pregrupisavanja pozicija i repozicioniranja zaposlenih, a zatim se kreira eksterni organizacioni dizajn iz kojeg nastaju različite pojavne forme međuorganizacionog dizajna kao što su mreže (interne, stabilne i dinamičke) (Miles \& Snow, 1992), organizacije bez granica (Ashkenas et al., 2002), meta-organizacije (Gulati, Phanish \& Tushman, 2012), organizacije orijentisane na aktere (učesnike) (Fjeldstad et al., 2012). Intenziviranje značaja interorganizacionog dizajna predstavlja rezultantu dva ključna faktora (Gulati, Phanish \& Tushman, 2012, str. 572):

1) prednosti od autsorsinga svih aktivnosti koje partneri iz okruženja mogu obaviti kvalitetnije i jeftinije, i

2) pristup jedinstvenom, specifičnom znanju koje je kompaniji potrebno a koje je dostupno u okruženju, izvan četiri zida kompanije.

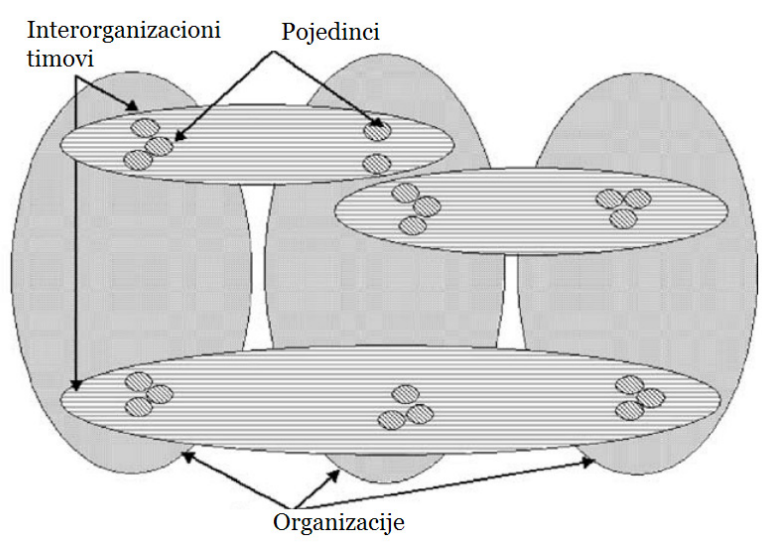

Slika 1: Međuorganizacioni dizajn Izvor: Higgins \& Maciariello (2004)

Zajedničko za sve oblike interorganizacionog dizajna jeste da su to izvedene forme birokratske organizacije koja je nadograđena novim osobinama kako bi osposobila organizacije da kroz saradnju sa partnerima odgovore na sve izazove iz okruženja (Petković \& Lukić, 2014). Njihovo funkcionisanje pored brojnih prednosti prate i određeni nedostaci koji se mogu pojaviti (Tabela 3).

\begin{tabular}{|l|l|}
\hline \multicolumn{1}{|c|}{ Prednosti } & \multicolumn{1}{|c|}{ Nedostaci } \\
\hline $\begin{array}{l}\text { Fleksibilna struktura } \\
\text { Mali broj hijerarhijskih } \\
\text { nivoa }\end{array}$ & $\begin{array}{l}\text { Fluidnost strukture može } \\
\text { uzrokovati konflikte } \\
\text { Nedostatak formalizacije može } \\
\text { Interno i eksterno ot- } \\
\text { voren sistem }\end{array}$ \\
$\begin{array}{l}\text { Visoko informatizovana } \\
\text { mange }\end{array}$ \\
$\begin{array}{l}\text { Učeća organizacija } \\
\text { Zaposleninacina imaju veliku } \\
\text { slobodu za generisanje } \\
\text { novih ideja } \\
\text { Težnja ka inovacijama }\end{array}$ & $\begin{array}{l}\text { i procedura može smanjiti } \\
\text { pouzdanost autputa } \\
\text { kulturama ne daje željene i } \\
\text { očekivane rezultate }\end{array}$ \\
\hline
\end{tabular}

Tabela 3. Ključne prednosti i nedostaci interorganizacionog dizajna

Izvor: Petković \& Lukić (2014)

\section{FAKTORI USPEHA MEĐUORGANIZACIONIH ODNOSA}

Upravljanje međuorganizacionim odnosima nije jednostavno. Kao što je Piter Draker isticao da je za dobru muziku bitno sinhronizovati svaki pojedinačni instrument u orkestru (Drucker, 1999), svi partneri u interorganizacionom odnosu treba da na fleksibilan način ostvare sopstvene ciljeve, a da se istovremeno realizuju i ciljevi zbog kojih je taj odnos formiran. Zajednički ciljevi i komplementarne sposobnosti su dobra početna osnova koja povezuje različite učesnike i daje im motiv za saradnju dok su kompatibilna kultura, uzajamno poštovanje, poverenje i podrška menadžmenta determinante koje određuju uspeh uspostavljenog odnosa (Mankin, Cohen \& Fitzgerald, 2004).

Da bi uspostavljeni međuorganizacioni odnosi dali rezultate koji se od njih očekuju, nameće se pitanje kako njima upravljati na adekvatan način. Vremenom su pored preduslova koji moraju biti ispunjeni za formiranje međuorganizacionih odnosa, identifikovani neki od ključnih faktora njihovog uspeha. Pre svega, na nivou svake kompanije koja stupa u interorganizacione odnose menadžment mora da pripremi organizaciju - njene procese, sistem vrednosti, stavova, pravila i normi, zaposlene, sistem nagrađivanja pomoću kojih će kompanija biti spremna i motivisana da dinamički stupa u različite vidove saradnje u zavisnosti od postavljenih strategijskih ciljeva. Upravljanje interorganizacionim odnosima podrazumeva i planski pristup procesu obuke zaposlenih, ali i menadžera na svim nivoima. Ovakvi programi obuke obuhvataju promenu u kognitivnoj i bihejvioralnoj sferi ponašanja zaposlenih, kroz sticanje novih znanja i iskustava, odnosno kroz razumevanje i prihvatanje novog organizacionog pristupa i realnosti iskazanih kroz nova organizaciona pravila, norme, značenja, rutine (McDermott \& Archibald, 2010).

Bitni organizacioni aspekti koji su od velikog značaja za uspeh međuorganizacionih odnosa su (Mankin, Cohen \& Fitzgerald, 2004, str. 11):

1) stepen formalizacije iskazan kroz pisana pravila, procedure, propise, zadatke;

2) delegiranje odgovornosti za upravljanje projektima i proces odlučivanja;

3) tehnologija, odnosno kako su aktivnosti saradnje podržane savremenim informaciono-komunikacionim tehnologijama.

Svaka složenija forma saradnje zahteva formalno definisana pravila, procedure, uloge i aktivnosti za različite učesnike kako bi svi koji su uključeni u određeni vid saradnje znali svoje uloge i dali svoj doprinos. Uspostavljeni međuorganizacioni odnosi zahtevaju intenzivu razmenu informacija i znanja između partnera, i samim tim je potrebno obezbediti više podrške pomoću informaciono-komunikacionih tehnologija. Što je veća neizvesnost zadataka, potrebna je veća količina ažurnih i pravovremenih informacija donosiocima odluka kako bi se ubrzao proces odlučivanja, poboljšao kvalitet donete odluke (Huxham \& Vangen, 2005) i postigle visoke performanse (Galbraith, 1973). Koordinacija, kao proces u kojem dve ili više organizacija zajedničkim snagama donose odluke, postaje dosta složenija u međuorganizacionom odnosu zbog velikog broja učesnika, njihovih različitih interesa, znanja, veština i intelektualnih sposobnosti, ali su i same odluke koje se donose složenije (Choi \& Robertson, 2013). Takođe, jedan od faktora uspeha jeste i međuorganizaciono poverenje koje se odnosi na očekivanja jedne organizacije da se druga organizacija neće ponašati oportunistički. Poverenje između partnera, njihova koordinacija i posvećenost ne samo da vode smanjenju transakcionih troškova već i rastu efikasnosti 
(Mirković \& Lukić, 2013). Takođe, za uspešno funkcionisanje uspostavljenog međuorganizacionog odnosa bitno je da:

1) učesnici imaju sposobnosti za samo-organizovanje,

2) postoje zajednička sredstva i unapred uspostavljeni mehanizmi pomoću kojih učesnici akumuliraju i dele resurse, $\mathrm{i}$

3) postoje protokoli, procesi i infrastruktura koja omogućava saradnju više učesnika. Zajedničkim delovanjem ovih elemenata stvara se organizacioni kontekst pomoću kojeg se postiže kreiranje zajedničke vrednosti, uspostavljanje zajedničkih normi, poverenja između učesnika i njihove posvećenosti u međuorganizacionom odnosu.

\section{ZAKLJUČAK}

Primenjujući poslovni model zasnovan na konceptu zajedničke vrednosti, kompanije nastoje da kreiraju vrednost ne samo za sebe, već i za društvenu zajednicu u kojoj posluju. Uspešni menadžeri su shvatili da društveni problemi, sa jedne strane, predstavljaju ograničavajuće faktore, ali da se, sa druge strane, u njima kriju brojne mogućnosti za dalji rast i razvoj, što su iskoristili, i kroz saradnju sa brojnim partnerima stvorili osnovu za kreiranje zajedničke vrednosti. Primena koncepta zajedničke vrednosti implicira brojne promene u kompaniji, koje počinju sa redefinisanjem strategije, pa preko redizajniranja modela organizacione strukture, da bi se na temelju uspostavljenog interorganizacionog odnosa (partnerstva) formirala neka nova forma organizacionog dizajna koja će podržati uspostavljeno partnerstvo. Te promene su uočljive pre svega u novim, interorganizacionim strategijama a posledično i u ostalim elementima dizajna kompanije kojeg čini struktura kao njegovo jezgro, a zatim i ostali elementi kao što su procesi, ljudski resursi, sistem nagrađivanja, liderstvo, kultura. Upravljanje interorganizacionim odnosima nije jednostavno, jer je potrebno uskladiti interese većeg broja učesnika. Lideri i menadžeri moraju biti svesni činjenice da uspeh interorganizacionih odnosa zavisi od velikog broja faktora: integracije različitih stilova menadžmenta, različitih sposobnosti učenja, odnosa poverenja među partnerima, posvećenosti partnera, samokontrole partnera, koordinacije i slično. Oni moraju naučiti kako da oblikuju ove faktore unutar svojih kompanija i kako da pripreme svoju kompaniju na saradnju sa drugima.

Obzirom da su istraživači iz različitih oblasti, ali i brojni lideri i menadžeri prepoznali mogućnost, potencijal i značaj činjenice da organizacioni rast i razvoj može da se ostvari primenom koncepta zajedničke vrednosti primenom strategija međuorganizacionih odnosa, realno je očekivati njegovu intenzivniju primenu u praksi. Posledično, međuorganizacioni odnosi i dizajn kao značajna poluga za primenu ovog koncepta će zasigurno dobiti na svom značaju i važnosti, kao i svi već pomenuti faktori koji utiču na uspeh uspostavljenog međuorganizacionog partnerstva.

\section{LITERATURA}

Ashkenas, R., Ulrich, D., Jick, T., \& Kerr, S. (2002). The Boundaryless Organization. San Francisco: Jessey-Bass.

Caliendo, H. (2012). Five major U.S. brands collaborating on plant-based PET, dostupno na http://www.plasticstoday. com/articles/Five-major-US-brands-collaborating-onplant-based-PET-0605201202, pristupljeno 29.01.2015.

Chandler, A. (1962). Strategy and Structure, Chapters in the history of the Industrial Enterprise. Cambridge: MIT Press.
Choi, T., \& Robertson, P. (2013). Deliberation and Decision in Collaborative Governance: A Simulation of Approaches to Mitigate Power Imbalance. Journal of Public Administration Research and Theory, 24, 495-518.

Daft, R. (2009). Organization Theory and Design. Mason. OH: South-Western College Publication.

Drucker, P. (1999). The new pluralism. Leader to Leader, 14, 1823.

Drucker, P. (2001). Moj pogled na menadžment. Novi Sad: Adizes.

Eriksen, B. (2006). Organization design constraints on strategy and performace. In: Burton et al. (Eds.) Organization Design: The Evolving State of the Art (165-181). Springer.

Fjeldstad, D., Snow, C., Miles, R., \& Lettl, C. (2012). The Architecture of Collaboration. Strategic Management Journal, 33, 734-750.

Galbraith, J. (1973). Designing complex organizations. Reading, MA: Addison-Wesley.

Galbraith, J. (2010). The Multi-Dimensional and Reconfigurable Organization. Organizational Dynamics, 39, 115-125.

Gulati, R., Planish, P., \& Tushman, M. (2012). Meta-organization design: rethinking design in interorganizational and community contexts. Strategic Management Journal, 33(6), 571586.

Gray, B. (1989). Collaborating: Finding Common Ground for Multiparty Problems. San Francisco: Jossey-Bass.

Grundei, J. (2006). Examining the relationship between trust and control in organizational design. U: Burton, R., et al. (Eds.) Organization Design: The Evolving State of the Art (43-67), Springer.

Higgins, K.L., \& Maciariello, J.A. (2004). Leading complex Collaboration in Network Organizations: A Multidisciplinary Approach. U: Beyerlein M., Johnson D., Beyerlein S. (Eds.) Building the Capabilities for Working Across Boundaries (203-243), Volume 10, Elsevier.

Huxham, C., \& Vangen, S. (2005). Managing to collaborate: The theory and practice of collaborative advantage. Abingdon, UK: Routledge.

Koput, K., \& Powell, W. (2004). Not Your Stepping Stone: collaboration and the Dynamics of Firm Evalution in the life sciences. U: Beyerlein M., Johnson D., Beyerlein S. (Eds.) Building the Capabilities for Working Across Boundaries (5983), Elsevier.

Kramer, M. (2012). Better ways of doing business: Creating shared value, dostupno na: http://www.theguardian.com/sustainable-business/blog/creating-shared-value-social-progressprofit , pristupljeno 30.01.2015.

Mankin, D., Cohen, S., \& Fitzgerald, S. (2004). Developing Complex Collaborations: Basic Principles to Guide Design and Implementation. U: Beyerlein M., Johnson D., Beyerlein S. (Eds.) Building the Capabilities for Working Across Boundaries (1-26), Elsevier.

Maltz, E., \& Schein, S. (2012). Cultivating Shared Value Initiatives: A Three Cs Approach. Journal of Corporate Citizenship, 47, 55-74.

Miles, R., \& Snow, C. (1992). Causes of Failure in Network Organizations. California Management Review, 53-72.

Mirković, V., \& Lukić, J. (2013). Klasterizacija malih i srednjih preduzeća kao determinanta konkurentnosti i šansa za oporavak srpske privrede. U: Lovreta S., Janićijević N. Konkurentnost preduzeća u Srbiji (449-468), Beograd: Ekonomski fakultet.

McDermott, R., \& Archibald, D. (2010). Harnessing Your Staff's Informal Networks. Harvard Business Review. 
Oliver, C. (1990). Determinants of interorganizational relationships: Integration and future directions. The Academy of Management Review, 15 (2), 241-265.

Ohmae, K. (1989). The Global Logic of Strategic Alliances. Harvard Business Review, 89(2), 143-154.

Osborn, R. N., Baughn, C. C. (1990). Forms of interorganizational governance for multinational alliances. Academy of Management Jorunal, 33, 503-519.

O'Leary, R., Bingham, L. B. (2007). Conclusion: Conflict and Collaboration in Networks. International Public Management Journal, 10(1), 103-109.

Porter, M. (1986). Competition in global industries. Boston: HBS Press.

Porter, M., \& Kramer, M. (2006). Strategy and Society: The Link Between Competitive Advantage and Corporate Social Responsibility. Harvard Business Review, December, 78-94.

Porter, M., \& Kramer, M. (2011). The Big Idea: Creating Shared Value. Harvard Business Review, 2-17.

Petković, M., \& Lazarević, S. (2012). Upravljanje interorganizacionim odnosima: dizajn centra zajedničkih usluga. Menadžment, 64, 55-64.
Petković, M., \& Lukić, J. (2014). New Organizational Forms Supported by the Information and Communication Technology: The Case of Serbian ICT Industry. Facta Universitatis - Economics and Organization, 11(2), 101-115.

Shumpeter, J. A. (1934). The Theory of Economic Development: An Inquiry into Profits, Capital, Credit, Interest, and Business Cycle. Cambridge: Harvard Business Press.

Schreiner, M., \& Corsten, D. (2004). Integrating Perspectives: A Multidimensional Construct of Collaborative capability. U: Beyerlein M., Johnson D., Beyerlein S. (Eds.) Building the Capabilities for Working Across Boundaries (125-161), Elsevier.

Todeva, E., \& Knoke, D. (2005). Strategic alliances \& models of collaboration. Management Decision, 43(1), 1-22.

Vaidyanathan, L., \& Scott, M. (2012). Creating Shared Value in India: The Future for Inclusive Growth. Corporate Social Responsibility: Practice, Theory, and Challenges, 37(2), 108113. 